\title{
Enhancing General Corrosion Resistance of Biomedical High Nitrogen Nickel-Free Stainless Steel by Nitric Acid Passivation
}

\author{
Yixun Yang ${ }^{1,2} \cdot$ Qingchuan Wang ${ }^{1} \cdot J_{\text {Jun }} \mathrm{Li}^{1,2} \cdot$ Lili Tan $^{1} \cdot \mathrm{Ke} \mathrm{Yang}^{1}$ \\ Received: 10 May 2019/ Revised: 21 June 2019 / Published online: 10 October 2019 \\ (C) The Chinese Society for Metals (CSM) and Springer-Verlag GmbH Germany, part of Springer Nature 2019
}

\begin{abstract}
A systematic study of nitric acid passivation was investigated to enhance the general corrosion resistance of biomedical high-nitrogen nickel-free stainless steels (HNSs). After passivation, the corrosion rate of HNS could dramatically reduce to $1 / 20$ of the untreated in $37{ }^{\circ} \mathrm{C} 0.9 \mathrm{wt} \% \mathrm{NaCl}$ solutions. Then, the passive film on $\mathrm{HNS}$ was analyzed by X-ray photoelectron spectroscopy. It was found that chromium enrichment in the passive film and nitrogen enrichment in the film $/ \mathrm{metal}$ interface contributed to the improvement in general corrosion resistance of HNS.
\end{abstract}

Keywords Stainless steel $\cdot$ Nitric acid passivation $\cdot$ General corrosion $\cdot$ Passive film

\section{Introduction}

With high strength, good toughness and excellent processing properties, metallic materials have been widely used in implants for human tissue repair. However, ions releasing from metallic implants cannot be avoided in human bodies. Some inflammatory responses and diseases are believed closely related to the excess dissolution of toxic ions from metallic implants [1-3]. Therefore, it is necessary to improve the general corrosion resistance of biomedical metals for improving their biocompatibility.

Nowadays, stainless steels are still widely used for clinical applications. With outstanding comprehensive performance, high-nitrogen nickel-free stainless steel (HNS) has broad application prospects as a new biomedical metal material [4-9]. In HNS, nitrogen $(\mathrm{N})$ is used to replace nickel (Ni) to stabilize austenite structure, which can effectively avoid the sensibilization and teratogenesis effects of $\mathrm{Ni}$ on human body [2,3]. To reduce the nitrogen alloying difficulty,

Available online at http://link.springer.com/journal/40195

Qingchuan Wang

qcwang11s@imr.ac.cn

1 Institute of Metal Research, Chinese Academy of Sciences, Shenyang 110016, China

2 School of Materials Science and Engineering, University of Science and Technology of China, Shenyang 110016, China
HNS always contains a large amount of manganese (Mn). However, Mn strongly increases the general corrosion of stainless steels [10], which would obviously reduce their biocompatibility. For example, the excess dissolution of $\mathrm{Mn}$ could induce a neurological disorder [1]. However, due to the excellent pitting corrosion resistance of HNSs, no study has been carried out to increase their corrosion resistance involving general corrosion.

On this basis, a systematic study of nitric acid passivation was reported to enhance the general corrosion resistance of HNS in this paper. Besides, X-ray photoelectron spectroscopy (XPS) analyses on passive films were applied for the mechanisms of passivation.

\section{Experimental}

The material used in this study was HNS with a nitrogen content of $0.92 \mathrm{wt} \%$, and its chemical compositions were (wt\%): N 0.92, Cr 18.30, Mn 14.90, Mo 2.60, Si 0.31, S 0.0094, $\mathrm{P} 0.010, \mathrm{C}<0.02$ and Fe balance. As a control material, chemical compositions of Ti6Al4V alloy were (wt\%): $\mathrm{Al}$ 6.01, V 3.97 and Ti balance. Before passivation, the samples of HNS were solution-treated at $1150{ }^{\circ} \mathrm{C}$ for $1 \mathrm{~h}$ and then water-quenched to room temperature. Ti6Al4V alloy is annealed at $700{ }^{\circ} \mathrm{C}$ for $1 \mathrm{~h}$ and then cooled in air. The preparation methods of samples were the same as our previous research [6]. 
Nitric acid passivation with various temperatures, concentrations and time was investigated. Samples were treated in $25 \mathrm{wt} \%$ nitric acid for $60 \mathrm{~min}$ at different temperatures $\left(25{ }^{\circ} \mathrm{C}, 50{ }^{\circ} \mathrm{C}\right.$ and $75{ }^{\circ} \mathrm{C}$ ), at $50{ }^{\circ} \mathrm{C}$ for $60 \mathrm{~min}$ in different concentrations (10 wt \%, $25 \mathrm{wt} \%$ and $40 \mathrm{wt} \%$ ), and in $25 \mathrm{wt} \%$ nitric acid at $50{ }^{\circ} \mathrm{C}$ for different time $(10 \mathrm{~min}$, $60 \mathrm{~min}, 300 \mathrm{~min}$ and $600 \mathrm{~min}$ ). And untreated samples of HNS and Ti6Al4V alloy were only exposed in air for $24 \mathrm{~h}$ at room temperature. Immersion test and potentiodynamic tests were conducted to investigate the effect of passivation. For immersion test, samples were immersed in $0.9 \mathrm{wt} \% \mathrm{NaCl}$ solution at $37{ }^{\circ} \mathrm{C}$ for 7 days with $0.8 \mathrm{~mL} / \mathrm{cm}^{2}$ immersion ratio according to the ISO 10993-15:2000 standard. And then their ions releasing concentration (IRC) was measured by atomic absorption spectroscopy (AAS) Z000. Potentiodynamic tests were performed in $0.9 \mathrm{wt} \% \mathrm{NaCl}$ solution at $37{ }^{\circ} \mathrm{C}$ using Gamry Reference 600 at a scan rate of $0.1667 \mathrm{mV} / \mathrm{s}$. XPS using the $\mathrm{Al} \mathrm{K} \alpha \mathrm{X}$-ray source was performed to analyze the passive film.
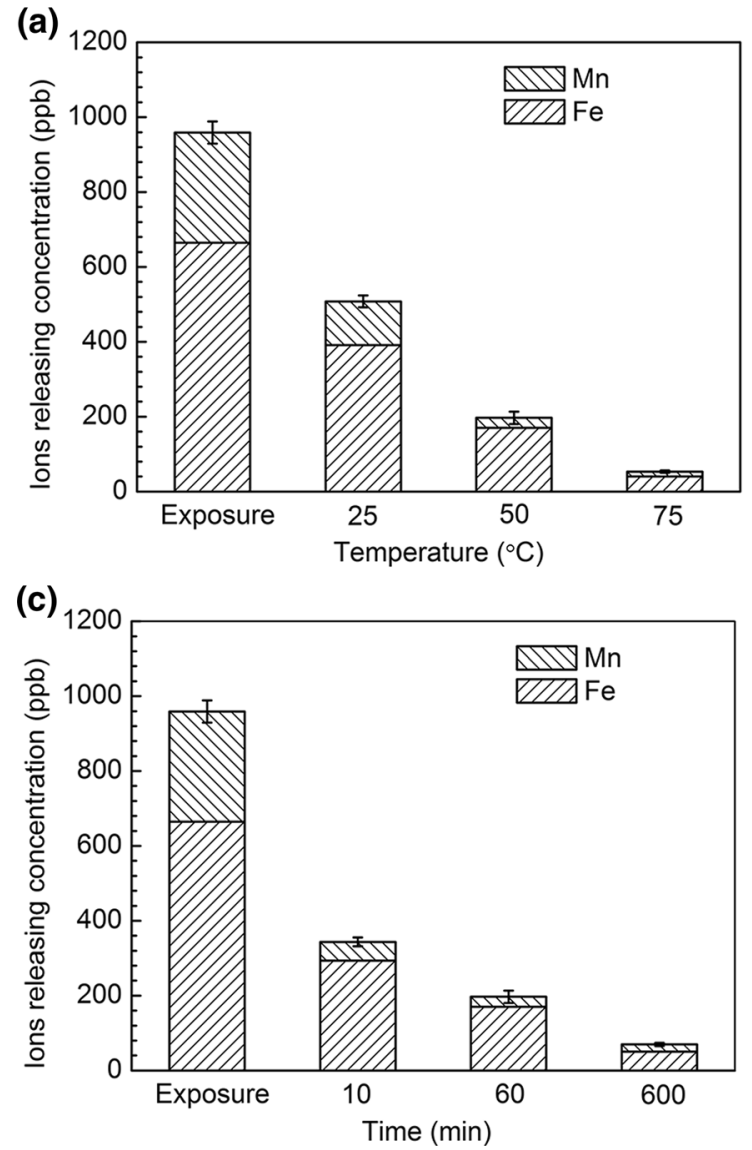

\section{Results and Discussion}

Figure 1 presents the effects of temperature, concentration and time of nitric acid passivation on the IRC. After passivation, a sharp reduction in the IRC was observed. As the passivation temperature increases, the IRC is greatly reduced. When the temperature is $75^{\circ} \mathrm{C}$, the IRC decreases to approximately $50 \mathrm{ppb}$, which is $1 / 20$ of the untreated HNS. With increasing nitric acid concentration, the difference is not significant. With the extension of time, a sharp descent was observed on the IRC. When the passivation time was $600 \mathrm{~min}$ at $50^{\circ} \mathrm{C}$, the IRC reaches the same order of magnitude with $75{ }^{\circ} \mathrm{C}$ for $60 \mathrm{~min}$. Figure $1 \mathrm{~d}$ shows the comparison of IRC of HNS before and after passivation. The results of Ti6Al4V alloy and 316L stainless steel before and after passivation are also shown here [11]. It is found that the ions are mainly Fe and Mn for HNS, Fe for 316L stainless steel and $\mathrm{Al}$ for Ti6Al4V alloy. Figure 1d also indicates that the general corrosion resistance of HNS after nitric acid passivation be much better than that of $316 \mathrm{~L}$ passivated by
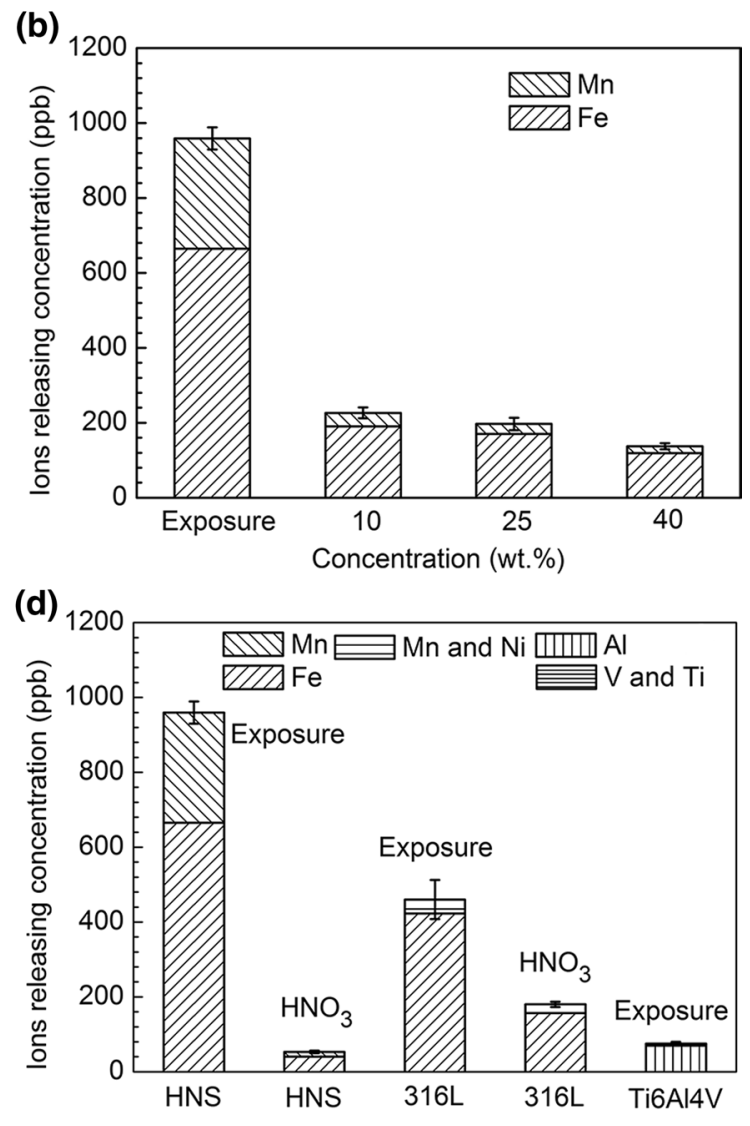

Fig. 1 Effects of temperature a, concentration $\mathbf{b}$ and time $\mathbf{c}$ of nitric acid passivation on ions releasing concentration of HNS; HNS and 316L stainless steel before and after nitric acid passivation and Ti6Al4V d; the error bars are total error 
common nitric acid passivation, and it be comparable to the Ti6Al4V alloy.

Effects of temperature, concentration and time of passivation were also investigated by electrochemical polarization. As shown in Fig. 2, it can be clearly seen that all of the factors have great influences on the polarization curves. The change in self-corrosion current density $\left(I_{\text {corr }}\right)$ is obtained by fitting the Tafel regions. As shown in Fig. 2, with the increase in temperature and concentration, $I_{\text {corr }}$ first decreases and then increases. As time goes on, $I_{\text {corr }}$ gradually decreases and then tends to be stable.

It is noteworthy that the effect of passivation estimated by $I_{\text {corr }}$ and IRC are inconsistent. It can be seen that, when self-corrosion potential $\left(E_{\text {corr }}\right)$ is low, the dissolutions of iron and manganese are the main reactions. However, according to potential- $\mathrm{pH}$ diagrams for the $\mathrm{Cr}-\mathrm{H}_{2} \mathrm{O}$ [12], a transition from $\mathrm{Cr}_{2} \mathrm{O}_{3}$ to $\mathrm{CrO}_{4}{ }^{2-}$ would occur above $0.4 \mathrm{~V}$ in a neutral solution, which means that the passive film would be dissolved at a potential above $0.4 \mathrm{~V}$. This phenomenon was also observed in the study of 304L stainless steels [13]. As shown in Fig. 2, the $E_{\text {corr }}$ of passivated HNS could reach approximately $0.5 \mathrm{~V}$, which means that there is a large difference for the general corrosion reactions. This difference might cause the inconsistency between these two methods. But further study is needed to clearly elucidate the underlying reason. As a result, it is not rigorous enough to evaluate the general corrosion resistance of HNS by $I_{\text {corr }}$ measurement.

In order to investigate the thickness and composition of passive film on HNS, XPS analyses were conducted. Figure 3 shows the depth distribution of oxygen $(\mathrm{O}), \mathrm{Cr}$ and $\mathrm{N}$ on temperature and time variation. Passive film thickness was determined by the oxygen content decreases to half of that at the surface. Figure $3 \mathrm{a}$ indicates that all the passive films' thickness of HNS after passivation is about $1 \mathrm{~nm}$, and it does not change with increasing temperature and concentration. In addition, it can be easily observed that both $\mathrm{Cr}$ and $\mathrm{N}$ are significantly enriched in passive films. It is noteworthy that $\mathrm{N}$ is significantly enriched in the film/ metal interface. With increasing temperature, both $\mathrm{Cr}$ and $\mathrm{N}$ contents' enrichment gradually increases. However, the nitric acid concentration has little effect on Cr enrichment, while $\mathrm{N}$ enrichment is strongly enhanced with increasing concentration.

Figure 4 shows the $\mathrm{Cr} 2 p_{3 / 2}$ spectra of samples, which consist of three peaks including metallic $\mathrm{Cr}, \mathrm{Cr}_{2} \mathrm{O}_{3}$ and $\mathrm{Cr}(\mathrm{OH})_{3}$. In addition, with increasing temperature, the $\mathrm{Cr}_{2} \mathrm{O}_{3}$
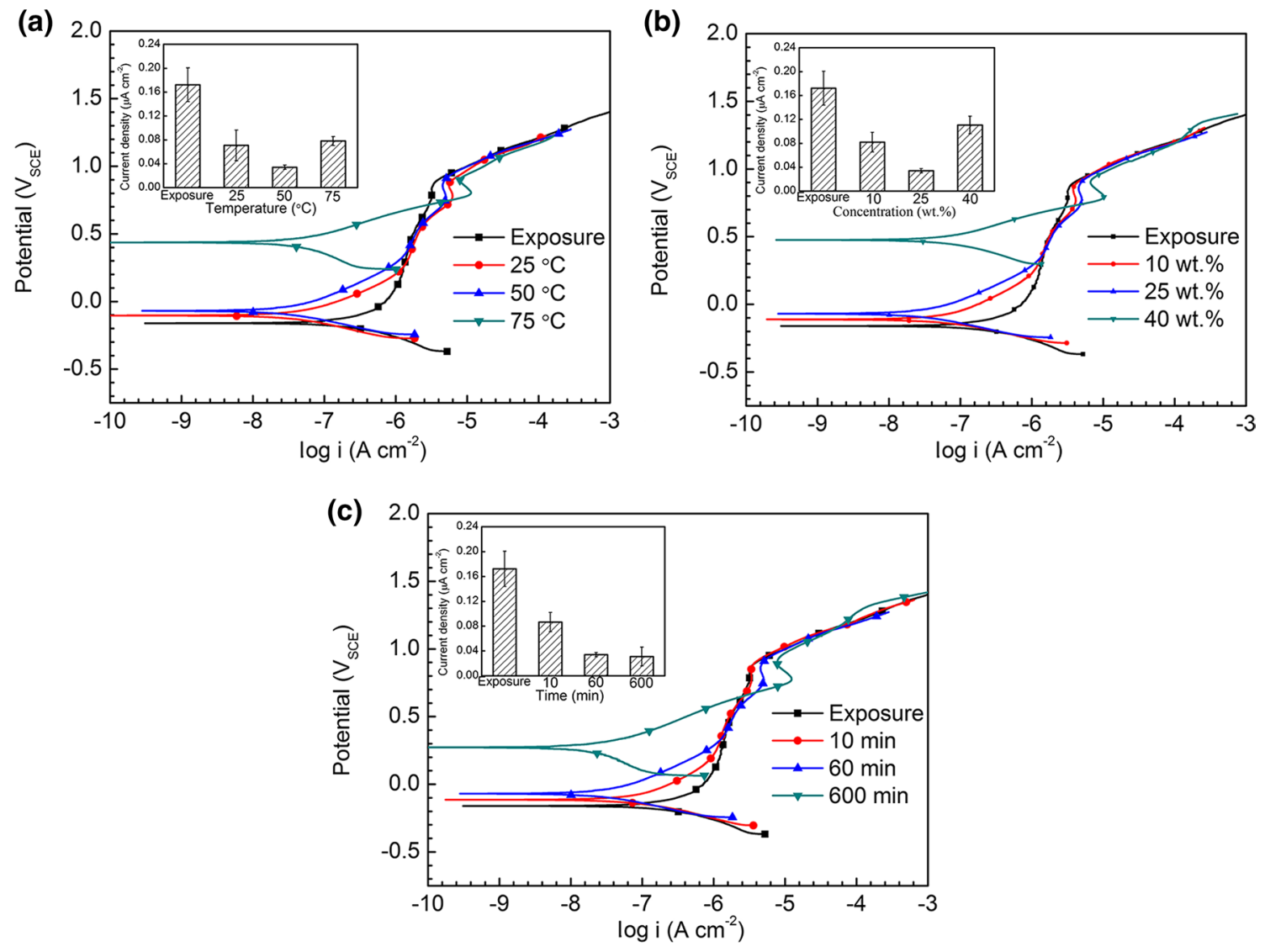

Fig. 2 Effects of temperature a, concentration $\mathbf{b}$ and time $\mathbf{c}$ of nitric acid passivation on polarization curves and self-corrosion current of HNS 

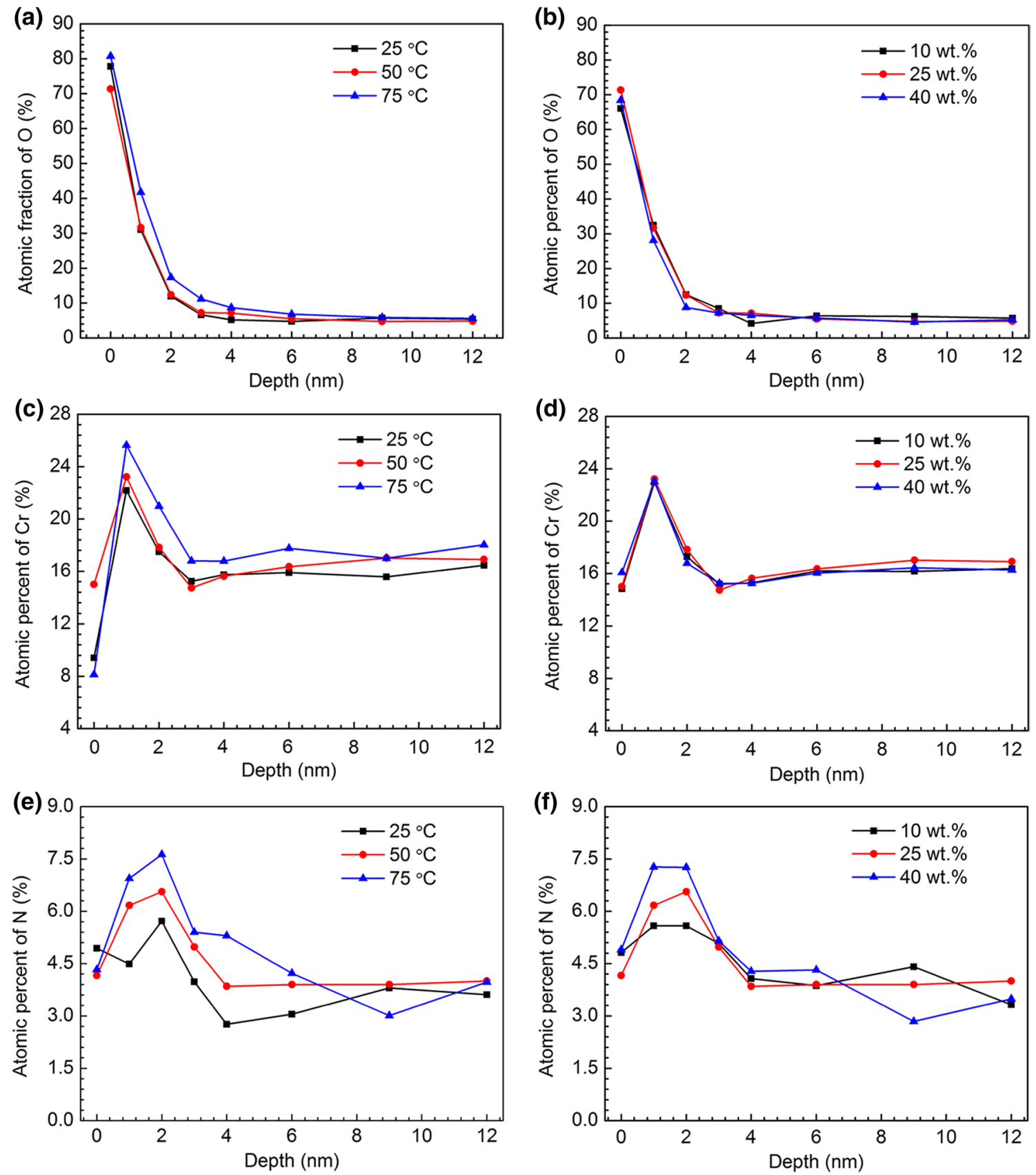

Fig. 3 Effects of temperature and concentration of nitric acid passivation on the depth profiles of $\mathrm{O} \mathbf{a}, \mathbf{b}, \mathrm{Cr} \mathbf{c}, \mathbf{d}, \mathrm{N}$ e, $\mathbf{f}$

content increases gradually in the passive film. But, after passivation at different concentrations of nitric acid, there is almost no significant change in the content of $\mathrm{Cr}$ at different states. According to the potential-pH diagram [14, 15], during nitric acid passivation, the $\mathrm{Cr}_{2} \mathrm{O}_{3}$ could stably exist in passive film, while both Fe and $\mathrm{Mn}$ would dissolute. At high temperature, nitric acid has stronger oxidation ability, and more metallic $\mathrm{Cr}$ can be oxidized to $\mathrm{Cr}_{2} \mathrm{O}_{3}$. Finally, more $\mathrm{Cr}_{2} \mathrm{O}_{3}$ forms in the passive film and the passive film becomes more protective. This should be the main reason for the strong influence of temperature to enhance the general corrosion of HNS, while concentration of nitric acid has little effect on it.

Figure 5 presents that $\mathrm{CrN}$ is the only form of $\mathrm{N}$ existed in both passive film and matrix of HNS. Hence, the distribution of the $\mathrm{CrN}$ in HNS is consistent with N. Many researchers also found the same results involving the existence of $\mathrm{N}$ in passive film of stainless steels by using XPS and secondary ion mass spectroscopy (SIMS) and demonstrated that $\mathrm{CrN}$ was short-range ordered amorphous $[6,7,16,17]$. At 

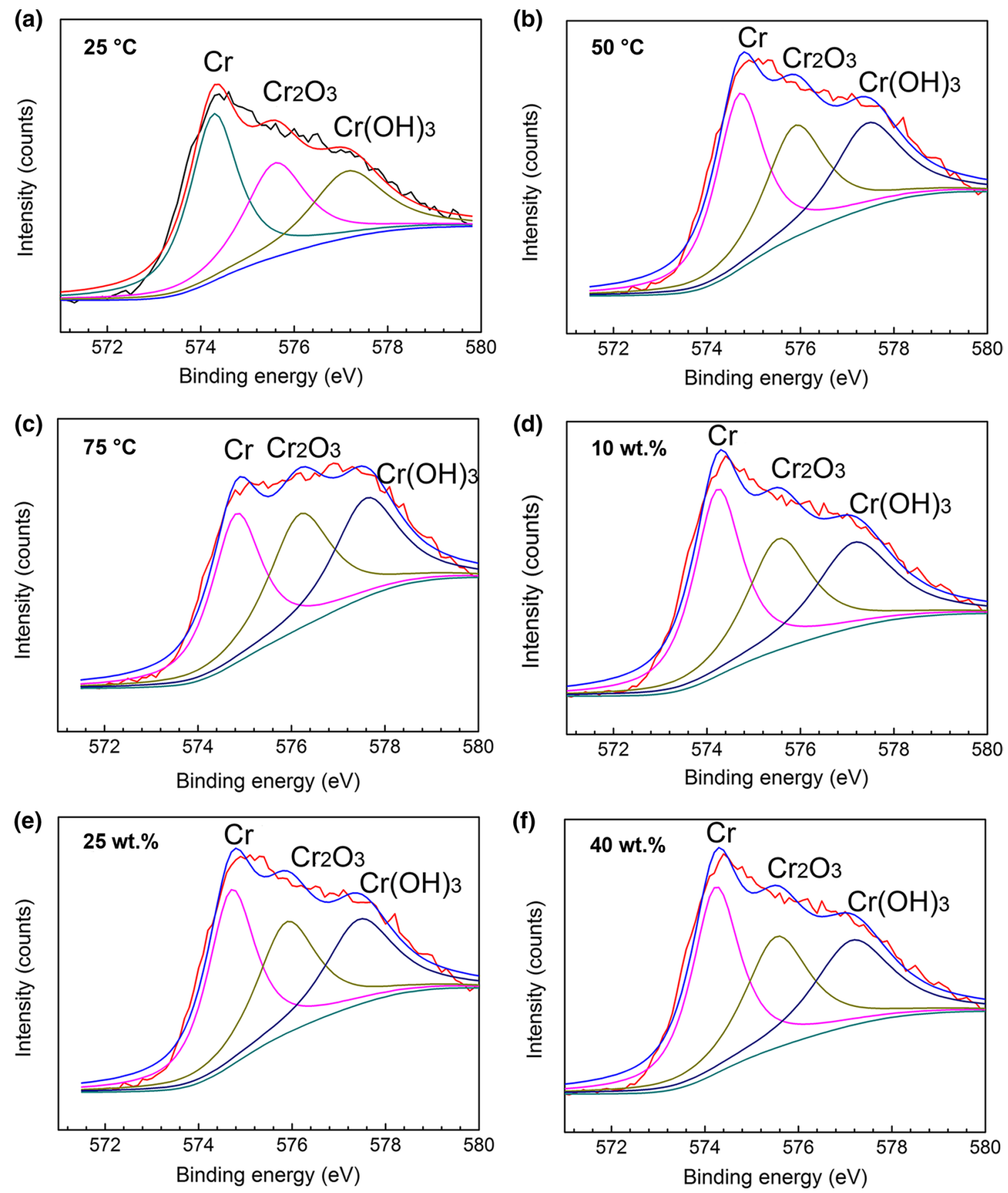

Fig. 4 XPS spectra of $\mathrm{Cr}$ for passive film after nitric acid passivation at $25^{\circ} \mathrm{C} \mathbf{a}, 50^{\circ} \mathrm{C} \mathrm{b}, 75^{\circ} \mathrm{C} \mathrm{c}, 10 \mathrm{wt} \% \mathbf{d}, 25 \mathrm{wt} \% \mathbf{e}$ and $40 \mathrm{wt} \% \mathbf{f}$

present, a number of investigations have been performed with regard to the active dissolution behavior of $\mathrm{N}$-alloyed stainless steel $[18,19]$. However, the effect of $\mathrm{N}$ on the general corrosion is still under debate. The study shows that the increase in $\mathrm{N}$ content could greatly enhance the resistance of metal dissolution [18]. A possible interpretation is that $\mathrm{N}$ is thermodynamically more stable than Fe and its dissolution reaction is a slow multi-electron process [17]. Besides, some researches show that the highly covalent character of the $\mathrm{Cr}-\mathrm{N}$ bonding could cause an increase in the activation energy for the dissolution of matrix [20]. However, N enrichment in the film/metal interface could decrease the ions releasing from the matrix of HNS. Therefore, although the nitric acid concentration has a little effect on $\mathrm{Cr}$ enrichment, the $\mathrm{N}$ enrichment could be enhanced by increasing concentration. Thus, owing to the $\mathrm{N}$ enrichment, the increase 

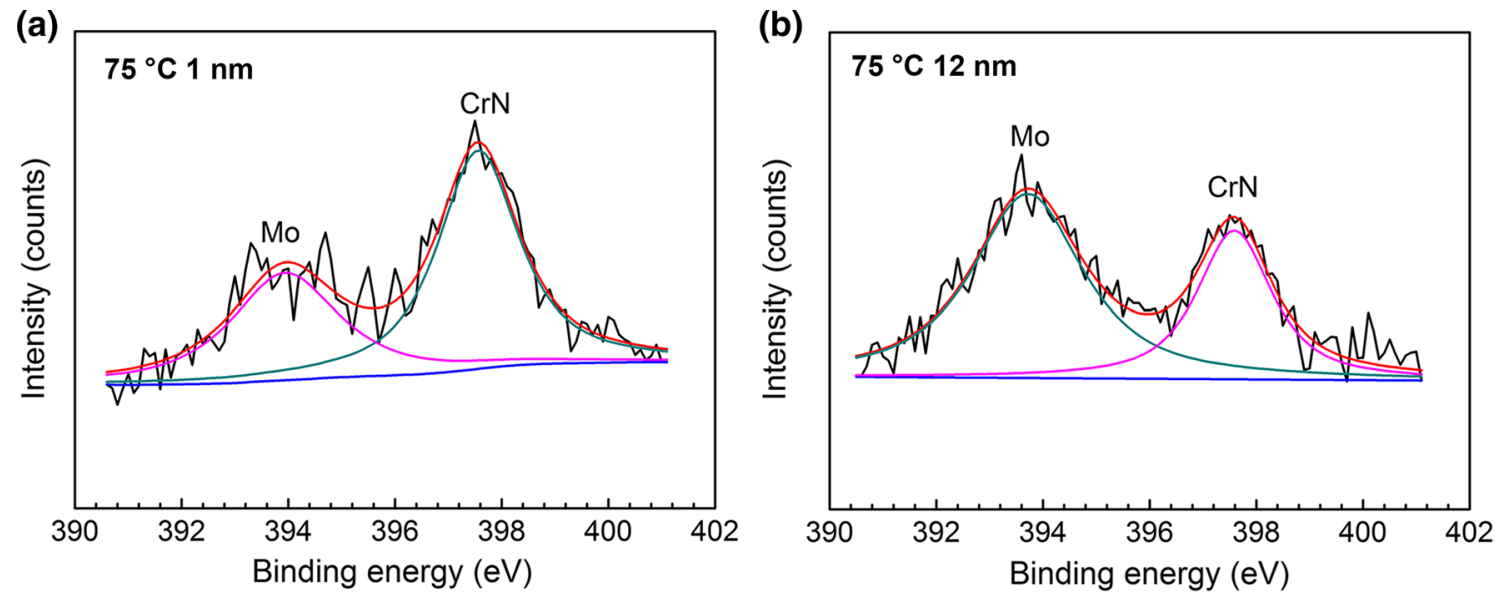

Fig. 5 XPS spectra of $\mathrm{N}$ on surface $\mathbf{a}$ and matrix $\mathbf{b}$ of HNS after nitric acid passivation

in nitric acid concentration could slightly improve the general corrosion resistance of HNS.

In addition, considering that the $\mathrm{N}$ enrichment in the film/ metal interface happens after both high temperature and high nitric acid concentration passivation, the significant increase in corrosion potential in Fig. 2 should be closely related to the $\mathrm{N}$ enrichment. On this basis, the chromium enrichment in the passive film and nitrogen enrichment in the film/metal interface play important roles in the improvement in general corrosion resistance of HNS after nitric acid passivation.

\section{Conclusions}

In summary, nitric acid passivation was systematically investigated for enhancing the general corrosion resistance of HNS. After passivation, the corrosion rate of HNS could dramatically reduce to $1 / 20$ of the untreated HNS and be comparable to the Ti6Al4V alloy. Cr enrichment in the passive film and $\mathrm{N}$ enrichment in the film/metal interface should be contributed to the improvement in general corrosion resistance of HNS.

Acknowledgements This work was supported by the National Natural Science Foundation of China (No. 51801220), the Key Program of China on Biomedical Materials Research and Tissue and Organ Replacement (No. 2016YFC1101804 and 2016YFC1100604) and the Shenyang Key R\&D and Technology Transfer Program (No. Z18-0-027).

\section{References}

[1] Q.Z. Chen, G.A. Thouas, Mater. Sci. Eng., R 87, 1 (2015)
[2] P. Wan, Y.B. Ren, B.C. Zhang, K. Yang, Mater. Sci. Eng., C 30, $1183(2010)$

[3] Y.B. Ren, K. Yang, B.C. Zhang, Mater. Lett. 59, 1785 (2005)

[4] H.C. Zhao, Y.B. Ren, J.H. Dong, X.M. Fan, K. Yang, Acta Metall. Sin. (Engl. Lett.) 29, 217 (2016)

[5] H.B. Li, Z.H. Jiang, H. Feng, S.C. Zhang, L. Li, P.D. Han, R.D.K. Misra, J.Z. Li, Mater. Des. 84, 1 (2015)

[6] Q.C. Wang, B.C. Zhang, Y.B. Ren, K. Yang, Corros. Sci. 145, 55 (2018)

[7] Q.C. Wang, B.C. Zhang, Y.B. Ren, K. Yang, Corros. Sci. 123, 351 (2017)

[8] F.Y. Dong, P. Zhang, J.C. Pang, Q.Q. Duan, Y.B. Ren, K. Yang, Acta Metall. Sin. (Engl. Lett.) 29, 140 (2016)

[9] Q.C. Wang, B.C. Zhang, Y.B. Ren, K. Yang, Acta Metall. Sin. 53, 1311 (2017). (in Chinese)

[10] M. Kemp, A.V. Bennekom, F.P.A. Robinson, Mater. Sci. Eng., A 199, 183 (1995)

[11] Q.C. Wang, Study on Microstructure and Properties of High Nitrogen Nickel-Free Biomedical Stainless Steel, Ph.D. Thesis, University of Chinese Academy of Sciences, 2017 (in Chinese)

[12] J.B. Lee, Corrosion 37, 467 (1981)

[13] J.B. Li, M.S. Zhang, J.W. Zhu, Corros. Sci. Prot. Technol. 18, 348 (2006). (in Chinese)

[14] M. Pourbaix, Lectures on Electrochemical Corrosion, 1st edn. (Plenum Press, New York, 2013)

[15] C.O.A. Olsson, D. Landolt, Electrochim. Acta 48, 1093 (2003)

[16] C.O.A. Olsson, Corros. Sci. 37, 467 (1995)

[17] K.L. Chao, H.Y. Liao, J.J. Shyue, S.S. lian, Metall. Mater. Trans. B 45, $381(2014)$

[18] H.Y. Ha, T.H. Lee, S.J. Kim, Electrochem. Acta 48, 432 (2003)

[19] Y. Fu, X.Q. Wu, E.H. Han, W. Ke, K. Yang, Z.H. Jiang, J. Electrochem. Soc. 155, C455 (2008)

[20] R.D. Willenbruch, C.R. Clayton, M. Oversluizen, D. Kim, Y. Lu, Corros. Sci. 31, 179 (1990) 